\title{
Use of the phaco tip technique for lens cleavage and removal during cataract surgery
}

\author{
This article was published in the following Dove Press journal: \\ Clinical Ophthalmology \\ 6 October 2016 \\ Number of times this article has been viewed
}

\author{
Yoichiro Masuda' \\ Kotaro Oki² \\ Hisaharu Iwaki ${ }^{3}$ \\ Toshinori Okamoto' \\ Hiroshi Tsuneoka ${ }^{4}$ \\ 'Department of Ophthalmology, \\ jikei University Katsushika Medical \\ Center, ${ }^{2}$ Oki Eye Surgery Center, \\ ${ }^{3}$ Iwaki Eye Clinic, ${ }^{4}$ Department of \\ Ophthalmology, Jikei University \\ School of Medicine, Tokyo, Japan
}

\begin{abstract}
Use of the phaco tip technique for lens cleavage and removal does not require manual hydrodissection using a syringe and cannula, or cortical removal using an irrigation/aspiration tip. The phaco tip is the only surgical instrument required for this technique. Its advantages include maintaining a stable intraocular pressure during cortical cleaving hydrodissection and lens removal, which includes the cortex.
\end{abstract}

Keywords: cataract surgery, hydrodissection, capsular block syndrome, FLACS, Dewey tip

\section{Introduction}

Normal surgical procedures for cataract removal require lens cortical-capsular cleavage (hydrodissection) using a syringe and cannula, lens nucleus removal using a phacoemulsification tip (phaco tip), and lens cortical removal using an irrigation/aspiration tip (I/A tip). Therefore, this requires the insertion and withdrawal of three different surgical instruments in order to complete these three surgical stages. As a result, this can lead to an increased risk of the collapse of the eye. Multiple studies that have examined manual hydrodissection and hydrodissection-related complications have reported that there is a significant increase in the intraocular pressure (IOP) during the procedures. ${ }^{1-7}$ Furthermore, when using femtosecond laser-assisted cataract surgery (FLACS), it has been reported that there is a manual hydrodissection induced capsular block syndrome because of the expansion of the endocapsular volume by the laser-induced intracapsular gas and cortical changes. ${ }^{8}$ Based on these findings, it is suggested that the use of a single instrument for all the three cataract surgical stages would likely improve stability of the IOP during hydrodissection and lens removal, including the cortex. Moreover, it is also likely that the number of complications would be reduced, as the use of a single instrument would also keep the safety irrigation IOP from the phaco tip sleeve which limit is the bottle-height dependent hydrostatic pressure, thereby helping to avoid an excessively high IOP and disturbance of the eye. ${ }^{9,10}$ In the present article, we describe a novel method that only uses the phaco tip for lens cleavage and removal.

\section{Surgical technique}

After completion of the initial steps of cataract surgery (incision; $2.7 \mathrm{~mm}$, ophthalmic viscosurgical device injection, and continuous curvilinear capsulorhexis [CCC]), a Dewey phaco tip (0.9 mm diameter; MicroSurgical Technology, Inc., Redmond, WA, USA) with a microsleeve (Alcon Laboratories, Inc., Fort Worth, TX, USA) is inserted into the anterior chamber. When using the phaco tip technique for lens cleavage and removal, once the superficial cortex and epinucleus have been removed to the maximum possible degree, the Dewey phaco tip is positioned on the peripheral lens at the
Correspondence: Yoichiro Masuda Department of Ophthalmology, jikei University Katsushika Medical Center, 6-4I-2 Aoto, Katsushika-ku Tokyo 125-8506, Japan

Tel +8I 336032 I I I

Fax +81336907474

Email massuuu@gmail.com 

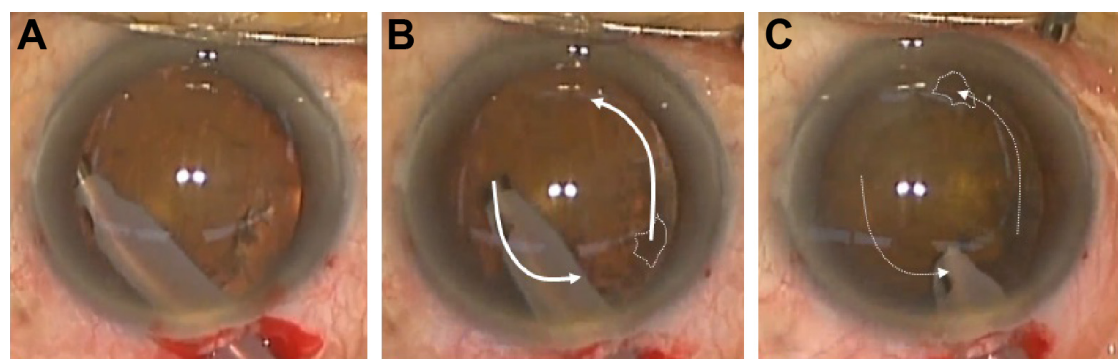

Figure I Lens cortical-capsular cleavage and cortex removal using a phaco tip.

Notes: (A) After removal of the superficial cortex and epinucleus over the maximum possible degree, the Dewey phaco tip is positioned on the peripheral lens at the capsulorhexis edge with the ultrasound energy set at zero and aspiration of the intraocular fluid used to induce the irrigation flow from the sleeve hole to the cortical-capsular layer. This procedure is repeated at several points on the capsulorhexis edge. Subsequently, after using the irrigation dynamic pressure to cleave the lens cortical-capsular layers, the lens can then be rotated (referred to as $\mathrm{iH}$ ). (B) and (C) After $\mathrm{iH}$, the phaco tip is used to rotate the lens nucleus circumferentially clockwise and counterclockwise several times in order to peel the residual lens cortex from the capsule. This makes it possible to use the phaco tip to aspirate the majority of the peeled cortex prior to nucleus removal. White arrows: direction of lens rotation; dashed line: the same position of the lens from the opacity pattern is used to enhance the lens rotation.

Abbreviation: $\mathrm{iH}$, irrigation dynamic pressure hydrodissection.

capsulorrhexis edge using zero ultrasound energy. Aspiration of the intraocular fluid is then performed to induce irrigation flow from the sleeve hole to the cortical-capsular layer (Figure 1A). By repeating this procedure at several points on the capsulorhexis edge, the irrigation dynamic pressure cleaves the cortical-capsular layers of the lens, which makes it possible to rotate the lens (which is referred to as the irrigation dynamic pressure hydrodissection $[\mathrm{iH}])$. In this stage, a Constellation Vision System (Alcon Laboratories, Inc.) is used that contains a Dewey phaco tip with a microsleeve. The phacoemulsification parameters are set as follows: vacuum system, Venturi pump; vacuum pressure, $200 \mathrm{mmHg}$; irrigation pressure, $50 \mathrm{~cm} \mathrm{H}_{2} \mathrm{O}$; and ultrasound power, zero.

The same parameters are utilized during the second stage of surgery, with the phaco tip used to rotate the lens nucleus circumferentially clockwise and counterclockwise (Figure 1B and C) several times in order to peel the residual lens cortex from the capsule. Consequently, this makes it possible to use the phaco tip to aspirate the majority of the peeled cortex prior to removal of the nucleus.

After cortical-capsular cleavage and removal of most of the cortex, the lens nucleus is removed during the third stage of surgery using the phaco tip, with the procedure based on the divide and conquer technique (Figure $2 \mathrm{~A}$ and B). ${ }^{11}$ During the final stage of the procedure, if needed, any residual cortex is aspirated using the phaco tip (Figure 2C) followed by removal of the entire lens via the use of only the phaco tip (Figure 2D). In order to prevent damage to the capsule when aspirating the cortex using the Dewey phaco tip: 1) we aspirated only the cortex by peeling it from the capsule, and thus did not aspirate the capsule and 2) as the posterior capsule is easily absorbed by phaco tip in cases with Wieger's ligament disturbance, infusion misdirection syndrome, etc., we aspirated the residual cortex after intraocular lens implantation using the I/A tip. Video S1 presents the technique in detail. Subsequently, the posterior chamber intraocular lens is implanted in the bag and the procedure is concluded as per the normal surgical procedure.

\section{Discussion}

In the current study, only a phaco tip was used for lens cleavage and removal during the phacoemulsification surgeries utilized for the cortical-capsular cleavage, and cortex and nucleus removal. The unique point of this technique is
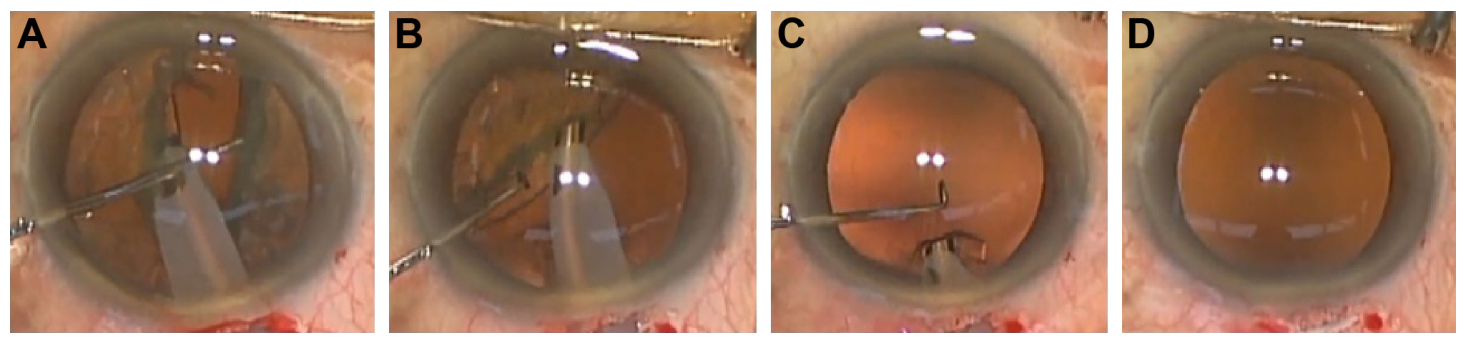

Figure 2 Nucleus and residual cortex removal using a phaco tip.

Notes: $(\mathbf{A})$ and $(\mathbf{B})$ After $\mathrm{iH}$ and the removal of most of the cortex, the phaco tip is used to remove the lens nucleus based on the divide and conquer technique. (C) During the final stage of the procedure, if needed, the phaco tip is used to aspirate any residual cortex. (D) Completion of the lens cleavage and removal is performed by using only the phaco tip. Abbreviation: $\mathrm{iH}$, irrigation dynamic pressure hydrodissection. 
that it removes the cortex in parallel with the $\mathrm{iH}$, which is carried out prior to the lens nucleus phacoemulsification. As the cortical capsular connection adhesive strength affects the time of the $\mathrm{iH}$, the procedure tends to be faster in cases with a harder versus a softer nucleus. As the Dewey tip has a smooth edge that does not cause rupture of the capsule due to attachment, tip placement on the posterior capsule is considered to be safe in cases that have residual cortex after the nucleus removal (Figure 3). ${ }^{12,13}$ This technique is also unique as it uses a circumferential nucleus rotation approach after the cortical-capsular cleavage. This weakens the lens cortical-capsular adhesive strength, which makes it possible to remove the majority of the cortex prior to the removal of the nucleus. As the aspiration opening of the phaco tip is larger than that of the I/A tip and the phaco tip can easily absorb the posterior capsule in situations in which there is no tension from the nucleus, in the past, the phaco tip has been previously considered to be unsuitable for cortical removal after the removal of the nucleus. In contrast to the common phacoemulsification approach, our technique can overcome this issue by aspirating the cortex prior to removal of the nucleus. Thus, the cortex can be removed without any absorption of the capsule, as the nucleus stretches the capsule centrifugally. Modern phacoemulsification machines provide stable irrigation pressure in the endocapsular space, which makes it possible to avoid the risk for capsular tears when removing the nucleus without the residual cortex.

The cause of capsular block syndrome has been considered to be due to the CCC block by the lens nucleus and the pressure of the trapped irrigation that occurs between the lens nucleus and the posterior capsule. Due to the

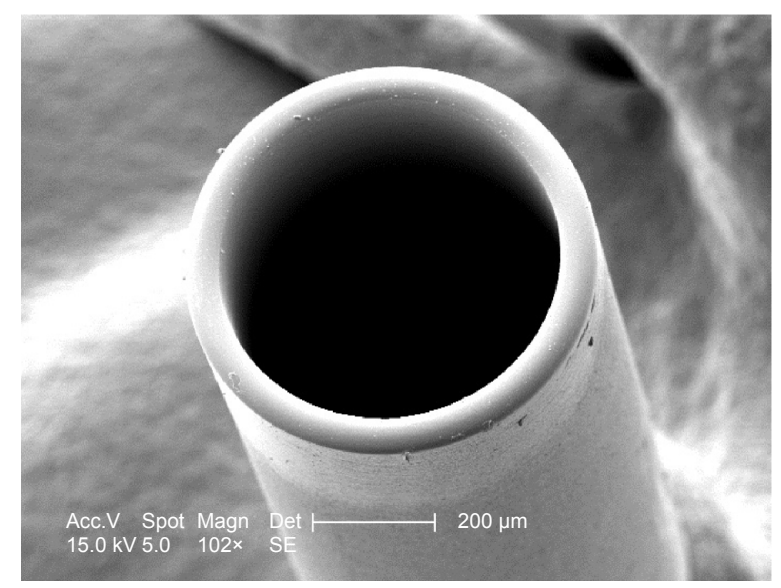

Figure 3 High magnification photo of the Dewey phaco tip.

Notes: As the Dewey tip has a smooth edge that does not cause rupture of the capsule due to the attachment, tip placement on the posterior capsule is considered to be safe in cases that have residual cortex after the nucleus removal. development of this high pressure, posterior capsule rupture can be elicited during manual hydrodissection. With our technique, however, the cortical removal in parallel with the $\mathrm{iH}$ produces space for flow passage around the $\mathrm{CCC}$, thereby contributing to the avoidance of the CCC block during the hydrodissection. In cases undergoing FLACS, it is very important to reduce the intracapsular gas prior to hydrodissection in order to avoid these high-pressure complications. Thus, when the cortical and intracapsular gas removal is performed in parallel with $\mathrm{iH}$, it ensures that FLACS can be performed safely compared to manual hydrodissection.

When using the phaco tip technique for lens cleavage and removal, it is not necessary to perform manual hydrodissection using a syringe and cannula or cortical removal using an I/A tip. Moreover, avoiding the use of multiple surgical instruments and bottle height-dependent maximum irrigation pressure promotes a stable IOP during hydrodissection and lens removal, including the cortex. In addition, the cortical and/or intracapsular gas removal in parallel with $\mathrm{iH}$ also contributes to the avoidance of capsular block syndrome. As this approach may be a beneficial option for phacoemulsification surgery, further studies that examine the safety and efficacy of the technique in various other types of cataract cases will need to be undertaken.

\section{Disclosure}

The authors report no conflicts of interest in this work.

\section{References}

1. Khng C, Packer M, Fine IH, Hoffman RS, Moreira FB. Intraocular pressure during phacoemulsification. J Cataract Refract Surg. 2006; 32(2):301-308.

2. Hurvitz LM. Posterior capsular rupture at hydrodissection (letter). J Cataract Refract Surg. 1991;17(6):866.

3. Ota I, Miyake S, Miyake K. Dislocation of the lens nucleus into the vitreous cavity after standard hydrodissection. Am J Ophthalmol. 1996; 121(6):706-708.

4. Miyake K, Ota I, Ichihashi S, Miyake S, Tanaka Y, Terasaki H. New classification of the capsular block syndrome. J Cataract Refract Surg. 1998;24(9):1230-1234.

5. Yoeh R, Theng J. Capsular block syndrome and pseudoexpulsive hemorrhage. J Cataract Refract Surg. 2000;26(8):1082-1084.

6. Kawasaki S, Suzuki T, Yamaguchi M, et al. Disruption of the posterior chamber-anterior hyaloid membrane barrier during phacoemulsification and aspiration as revealed by contrast-enhanced magnetic resonance imaging. Arch Ophthalmol. 2009;127(4):465-470.

7. Kawasaki S, Tasaka Y, Suzuki T, et al. Influence of elevated intraocular pressure on the posterior chamber-anterior hyaloid membrane barrier during cataract operations. Arch Ophthalmol. 2011;129(6):751-757.

8. Roberts TV, Sutton G, Lawless MA, Jindal-Bali S, Hodge C. Capsular block syndrome associated with femtosecond laser-assisted cataract surgery. J Cataract Refract Surg. 2011;37(11):2068-2070.

9. Eriksson A, Koranyi G, Sereqard S, Philipson B. Risk of acute suprachoroidal hemorrhage with phacoemulsification. J Cataract Refract Surg. 1998;24(6):793-800. 
10. Matsuo K. [Surgical outcomes of non-hydrodissection phacoemulsification and aspiration: removal of the lens fiber cell layer]. Jpn JOphthalm Surg. 2008;32:97-102. Japanese.

11. Gimbel HV. Divide and conquer nucleofractis phacoemulsification: development and variations. J Cataract Refract Surg. 1991;17(3): 281-291.
12. Meyer JJ, Kuo AF, Olson RJ. The risk of capsular breakage from phacoemulsification needle contact with the lens capsule: a laboratory study. Am J Ophthalmol. 2010;149(6):882-886.

13. Dewey S. Ultrasonic polishing of the posterior capsule with the Dewey radius tip. Tech Ophthalmol. 2006;4(4):139-148. 


\section{Supplementary material}

Video SI Use of the phaco tip technique for lens cleavage and removal.

\section{Publish your work in this journal}

Clinical Ophthalmology is an international, peer-reviewed journal covering all subspecialties within ophthalmology. Key topics include: Optometry; Visual science; Pharmacology and drug therapy in eye diseases; Basic Sciences; Primary and Secondary eye care; Patient Safety and Quality of Care Improvements. This journal is indexed on

Submit your manuscript here: http://www.dovepress.com/clinical-ophthalmology-journal

\section{Dovepress}

PubMed Central and CAS, and is the official journal of The Society of Clinical Ophthalmology (SCO). The manuscript management system is completely online and includes a very quick and fair peer-review system, which is all easy to use. Visit http://www.dovepress.com/ testimonials.php to read real quotes from published authors. 